\title{
DIVERSIDADE EM CONTEXTO EDUCATIVO: PRÁTICAS DESENVOLVIDAS POR UMA ESCOLA PÚBLICA SUL-MATO-GROSSENSE
}

\author{
DIVERSITY IN EDUCATIONAL CONTEXT: PRACTICES DEVELOPED BY A SUL-MATO- \\ GROSSENSE PUBLIC SCHOOL
}

Josiane Peres Gonçalves ${ }^{1}$

Marta Claudiane Ferreira ${ }^{2}$

\begin{abstract}
Resumo: A pesquisa tem por finalidade identificar as representações sociais e práticas desenvolvidas por uma escola pública do Estado de Mato Grosso do Sul em relação à diversidade dos alunos de anos iniciais do ensino fundamental. A linha teórica envereda-se principalmente por meio de discussões e conceitos de alguns exemplos de diversidades podendo ser entendidas como: socioeconômica, de inclusão, de gênero, entre outras. A pesquisa de campo foi realizada mediante gravação de entrevistas com quatro participantes sendo: uma gestora escolar, duas professoras e uma secretária escolar. Os resultados indicam que as representações sociais das profissionais da educação são de que as várias formas de diversidade existentes na escola não interferem em suas práticas de atuação, pois participam de um processo de formação continuada sobre essas temáticas. Assim, as educadoras se aproximam dos alunos, conhecem suas realidades fora da escola e assim estabelecem vínculos entre a instituição escolar, o aluno e a família. Diante dessa união, evidencia-se que a escola pesquisada tem cumprido um importante papel social, diante da diversidade que caracterizam os integrantes da comunidade escolar.
\end{abstract}

Palavras-chave: Representações Sociais. Práticas escolares. Diversidade.

\begin{abstract}
The research aims to identify the social representations and practices developed by a public school in the State of Mato Grosso do Sul in relation to the diversity of students from the first years of elementary school. The theoretical line is focused mainly through discussions and concepts of some examples of diversities and can be understood as: socioeconomic, inclusion, gender, among others. Field research was done by recording interviews with four participants: a school manager, two teachers and a school secretary. The results indicate that the social representations of education professionals are that the various forms of diversity that exist in the school do not interfere in their practices, since they participate in a process of continuous formation on these themes. Thus, educators approach students, know their realities outside of school and thus establish links between the school institution, the student and the family. Faced with this union, it is evident that the researched school has fulfilled an important social role, given the diversity that characterizes the members of the school community.
\end{abstract}

Keywords: Social representations. School practices. Diversity.

\footnotetext{
${ }^{1}$ Doutora com Pós-Doutorado em Educação pela Pontifícia Universidade Católica do Rio Grande do Sul (PUCRS). Professora Permanente do Programa de Pós-graduação em Educação da Universidade Federal de Mato Grosso do Sul. Líder do Grupo de Estudo e Pesquisa em Desenvolvimento, Gênero e Educação (GEPDGE).

${ }^{2}$ Mestranda do Programa de Pós-graduação em Educação da Universidade Federal de Mato Grosso do Sul. Integrante do GEPDGE. Atuou como bolsista de iniciação científica PIBIC/CNPq no curso de graduação em Pedagogia da UFMS.
} 


\section{INTRODUÇÃO}

O presente artigo aborda sobre as diversidades existentes na escola e as representações e práticas dos profissionais da educação em relação às diferenças dos alunos. Dessa forma, torna-se importante analisar os conceitos de representações sociais e diversidade, conforme apresentados na sequência.

Ao abordarmos representações sociais, destacamos que se tratam de veias de conhecimento geralmente baseadas no senso comum, pois "[...] dar sentido ao mundo é uma força poderosa e inevitável na vida em sociedade" (SPINK ; MEDRADO, 1999, p. 22). Para tanto, é possível afirmar que as representações podem ter o poder de moldar maneiras de agir e pensar de determinados indivíduos de uma sociedade. São conhecimentos muitas vezes herdados de costumes, crenças, valores familiares entre outros, que geralmente cultivamos e repassamos de uma geração para outra. Para Jodelet (1985), as representações sociais são socialmente fabricadas e compartilhadas, resultando em fenômenos sociais que buscam compreensão a partir das funções ideológicas e simbólicas a que se enquadram, tendo como forma de acesso e veiculação os meios de comunicação em massa.

Em relação às representações sociais específicas de um ser humano, devemos antes entender em qual contexto social o mesmo foi concebido, e quais foram os ambientes que este indivíduo cresce ou cresceu. De acordo com Forneiro (1998, p. 233) o ambiente é visto como:

\footnotetext{
[...] um todo indissociável de objetos, odores, formas, cores, sons e pessoas que habitam e se relacionam dentro de uma estrutura física determinada, que contém tudo e que, ao mesmo tempo, é contida por todos esses elementos que pulsam dentro dele como se tivessem vida. [...] o ambiente "fala", transmite sensações, evoca recordações, passa-nos segurança ou inquietação, mas nunca nos deixa indiferentes.
}

Diante de tal pressuposto, supõe-se que o ambiente escolar contribua no perpetuamento de vários tipos de representações sociais, já que a grande maioria da população brasileira participou, continuam participando ou farão parte do contexto escolar, mesmo porque existem leis, como a de n.12.796/2013, que alterou a lei de n. 9.394, de 20 de dezembro de 1996 presente na LDB (Leis de Diretrizes e Bases), que obriga toda criança e adolescente entre 4 e 17 anos de idade a estarem devidamente matriculados pelos familiares ou responsáveis, em uma unidade escolar (BRASIL, 2013). 
Ao tratarmos de ambiente escolar, deve-se levar em consideração o conjunto de indivíduos, cada qual, carregando consigo suas diferenças e identidades. Ao abordar sobre diferença, Louro (2008, p.22) se expressa da seguinte maneira: "Não, a diferença não é natural, mas sim naturalizada. A diferença é produzida através de processos discursivos e culturais. A diferença é ensinada". Para Silva (2000, p. 86), “[...] a identidade e a diferença são estreitamente dependentes da representação" e, nessa perspectiva, o mesmo autor faz uma súmula, pontuando como ele define "[...] o que não é, e o que é identidade":

\begin{abstract}
Primeiramente, a identidade não é uma essência; não é um dado ou um fato - seja da natureza, seja da cultura. A identidade não é fixa, estável, coerente, unificada, permanente. A identidade tampouco é homogênea, definitiva, acabada, idêntica, transcendental. Por outro lado, podemos dizer que a identidade é uma construção, um efeito, um processo de produção, uma relação, um ato performativo. A identidade é instável, contraditória, fragmentada, inconsistente, inacabada. A identidade está ligada a estruturas discursivas e narrativas. A identidade está ligada a sistemas de representação. A identidade tem estreitas conexões com relações de poder. (SILVA, 2000, p. 89).
\end{abstract}

Nesse sentido, a escola recebe diariamente pessoas (adultos e crianças), de várias idades, que levam consigo suas experiências de vida, contextos sociais distintos e níveis escolares diferenciados e que constituem o movimento vital da escola, sendo, alunos, professores, zeladores, inspetores, diretores entre muitos outros, formando assim uma imensa diversidade. Diante desse contexto, é necessário que predomine, entre os diversos representantes da comunidade escolar, o respeito às diferenças e identidades de cada ser humano que ali convive, tendo em vista que "[...] reconhecer a diversidade significa aceitar a ideia de que ser diferente não indica ser desigual” (GOELLNER, 2010, p. 72).

Partindo do princípio que o ambiente escolar é um dos principais pontos de agrupamento das várias formas de diversidades existentes na sociedade, seja ela socioeconômica, de gênero, étnica, de inclusão, de sexualidade, entre muitas outras, então "[...] apreender a escola como construção social implica, assim, compreendê-la no seu fazer cotidiano, onde os sujeitos não são apenas agentes passivos diante da estrutura. Ao contrário, trata-se de uma relação em contínua construção.” (DAYRELL, 1996, p. 2).

Sob esse prisma, a escola não somente é vista, pelas crianças e seus familiares, como uma obrigatoriedade imposta pelas leis vigentes do governo, mas que é também pensada como uma possibilidade de transformação de vida e elevação do nível econômico, principalmente para as classes de baixa renda. E apesar de todas as questões de poderes políticos que englobam as instituições educativas, a diversidade socioeconômica presente na escola comtempla uma melhoria de condições de vida que pode ser adquirida através dos estudos, pois se tratando desse papel social, a escola torna-se "[...] a esperança de um emprego melhor, ou uma certa estabilidade ocupacional.” (DAYRELL, 1996, p. 23).

A lei presente no artigo 205 da Constituição Federal de 1988 estabelece que a educação pública brasileira "é direito de todos", incluindo assim todas as pessoas com necessidades especiais, 
seja esta física ou cognitiva, essa diversidade passou a ter destaque maior a partir do início dos anos de 1990, abrindo um leque para mais uma diversidade dentro da instituição escolar: a de inclusão dos alunos com especificidades, chamando a atenção do governo para elaboração de políticas públicas com o intuito tanto de nortearem os profissionais da educação, assim como servir como respaldo para garantir ao sujeito com necessidades especiais o direito a escola pública.

Isso só foi possível mediante vários estudos de grandes pesquisadores como: Jean Piaget, Emília Ferrero, Vigotsky entre outros. Assim o governo brasileiro direcionou olhares para esse público e formulou leis que amparam esses alunos. Desse modo, conforme pautado na Declaração de Salamanca (1994, p.1):

Toda criança tem direito fundamental à educação, e deve ser dada a oportunidade de atingir e manter o nível adequado de aprendizagem, toda criança possui características, interesses, habilidades e necessidades de aprendizagem que são únicas, sistemas educacionais deveriam ser designados e programas educacionais deveriam ser implementados no sentido de se levar em conta a vasta diversidade de tais características e necessidades, aqueles com necessidades educacionais especiais devem ter acesso à escola regular, que deveria acomodá-los dentro de uma Pedagogia centrada na criança, capaz de satisfazer a tais necessidades, escolas regulares que possuam tal orientação inclusiva constituem os meios mais eficazes de combater atitudes discriminatórias criando-se comunidades acolhedoras, construindo uma sociedade inclusiva e alcançando educação para todos; além disso, tais escolas provêm uma educação efetiva à maioria das crianças e aprimoram a eficiência e, em última instância, o custo da eficácia de todo o sistema educacional.

Dentre as mais variadas Leis que regem a Educação Especial, foi a Declaração de Salamanca, realizada na Espanha no ano de 1994, sendo esta uma das primeiras discussões que possibilitaram uma abertura para que pessoas que possuem algum tipo de especificidade pudessem atuar na sociedade como cidadãos de direitos, igualando-os assim, a outros grupos da sociedade que não necessitam de atendimento especial. A referida declaração tratou de especificar como devem ser realizadas e quais devem ser os suportes para que seja efetivada a Educação Inclusiva.

Quanto à diversidade de gênero nas escolas, Louro (2008, p. 8) afirma que “[...] a construção dos gêneros e das sexualidades dá-se através de inúmeras aprendizagens e práticas, insinua-se nas mais distintas situações, é empreendida de modo explícita ou dissimulada por um conjunto inesgotável de instâncias sociais e culturais." Sob a perspectiva da diversidade de gênero, Scott (1995) destaca que:

[...], o termo "gênero" também é utilizado para designar as relações sociais entre os sexos. Seu uso rejeita explicitamente explicações biológicas, como aquelas que encontram um denominador comum para diversas formas de subordinação feminina, nos fatos de que as mulheres têm a capacidade para dar a luz e os homens têm força muscular superior. Em vez disso, o termo "gênero" torna-se uma forma de indicar " construções culturais" - a criação inteiramente social de ideias sobre os papéis adequados aos homens e as mulheres. (SCOT'T, 1995, p. 75). 
Dessa forma, a identidade de gênero que um sujeito adota esta relacionada com a maneira como ele se identifica dentro da sociedade enquanto ser social, para Scott (1995, p. 5), o gênero pode ser conceituado como "[...] toda e qualquer construção social, simbólica, culturalmente relativa, da masculinidade e da feminilidade. Ele define-se em oposição ao sexo, que se refere à identidade biológica dos indivíduos". Esse conceito, apontado pela renomada autora, vai ao encontro das ideias de Schmidt (2000, p. 95), por entender que é preciso estar ciente que "[...] falar sobre gênero é falar sobre diferença sexual e cultural”.

Lembrando que todos esses processos de construção do sujeito também podem acontecer dentro das instituições escolares que englobam a diversidade de gênero e a diversidade sexual, compreendo que uma não possui o mesmo conceito da outra, mas que ambas têm relação entre si e, nesse sentido, Louro (1997, p. 49) elucida que:

\begin{abstract}
Quando afirmamos que as identidades de gênero e as identidades sexuais se constroem em relação, queremos significar algo distinto e mais complexo do que uma oposição entre dois polos; pretendemos dizer que as várias formas de sexualidade e de gênero são interdependentes, ou seja, afetam umas as outras.
\end{abstract}

A diversidade sexual se sobrepõe nas escolas, já que nela estão presentes indivíduos em desenvolvimento contínuo em todos os aspectos (social, psicológico e físico). Sendo assim, desde muito pequenas, as crianças almejam entender melhor sua sexualidade e ao longo da vida buscam definir com quem gostam de se relacionarem. O Referencial Curricular Nacional, elaborado pelo Ministério da Educação destaca que:

\begin{abstract}
A sexualidade tem grande importância no desenvolvimento e na vida psíquica das pessoas, pois independentemente da potencialidade reprodutiva, relaciona-se com o prazer, necessidade fundamental dos seres humanos. Nesse sentido, é entendida como algo inerente, que está presente desde o momento do nascimento, manifestando-se de formas distintas segundo as fases da vida. Seu desenvolvimento é fortemente marcado pela cultura e pela história, dado que cada sociedade cria regras que constituem parâmetros fundamentais para o comportamento sexual dos indivíduos. (BRASIL, 1998, p. 17).
\end{abstract}

Com isso, o desenvolvimento da sexualidade se torna algo crucial para a criança e o adolescente ainda que, devido aos fatores culturais, a sexualidade é entendida a partir de alguns tabus e preconceitos que geralmente provém de outros tipos de diversidades, como a religiosa, familiar, étnica e cultural. 
A diversidade familiar vem se transformando ao longo dos anos, pois na atualidade quando tratamos de família não mais devemos pensar em uma constituição nuclear de pessoas brancas: pai, mãe e filhos (ARIÈS, 1981). E sim abranger essa concepção para muito além desse olhar. Para Palma e Strey (2015, p. 3):

A instituição família se transformou, logo, outras instituições sociais precisaram se transformar também, e a escola é uma delas. Estando as famílias constituídas por gays e lésbicas legitimadas, as crianças provenientes dessas famílias foram visibilizadas. A escola passou a conviver então, com muitas outras famílias, que não as tradicionais constituídas por pai e mãe. E a educação brasileira precisou ampliar seus conceitos também.

Sendo assim, houve a necessidade de reconhecer esses novos modelos de famílias, bem como respeitá-los enquanto instituição familiar. Ao tratar de diversidade étnica-cultural, primeiramente devemos levar em consideração que o Brasil recebeu, nos últimos anos, milhares de imigrantes de outros países, como divulgado no site Folha De São Paulo que descreve que:

Segundo o relatório divulgado no dia 19 de junho de 2018, pelo Alto Comissariado das Nações Unidas para Refugiados (ACNUR), somando-se os refugiados no Brasil, que são 10.264 mais os que entraram com pedidos de refúgio e aguardam decisão (85.746) e os estrangeiros que receberam outro tipo de proteção (no caso do Brasil, permissão temporário de residência) o número chegou a 148.645 em 2017, uma alta de $118 \%$ em relação ao ano anterior. (FOLHA DE SÂO PAULO, 19 de jun. 2018).

Sendo em sua maioria refugiados que no geral se acomodam nas regiões periféricas das cidades, muitas destas pessoas ainda se encontram em idade escolar e, portanto, precisam estar inseridas em alguma instituição escolar. Vale ressaltar que o Brasil é também um país único e imenso, e que para cada região do país existe uma grande diversidade cultural. Ao enveredar-se nessa perspectiva, Fernandes (2005, p. 379) explica da seguinte maneira:

\footnotetext{
Muitos antropólogos, historiadores e cientistas sociais, a exemplo de Gilberto Freyre, Sérgio Buarque de Holanda e Fernando de Azevedo e, mais recentemente, Florestan Fernandes, Darcy Ribeiro, Roberto da Matta, Alfredo Bosi e Renato Ortiz, já se preocuparam em definir e compreender a cultura brasileira em suas múltiplas dimensões. Todos, a par de suas diferentes posições político-ideológicas, são unânimes em concordar que a característica marcante de nossa cultura é a riqueza de sua diversidade, resultado de nosso processo histórico-social e das dimensões continentais de nossa territorialidade.
}

Pensando na ideia de que os habitantes imigram e migram de uma região para outra em busca de uma vida melhor, e visto que em geral a escola é percebida para além da obrigatoriedade, 
esses sujeitos se articulam também nesse novo meio escolar e leva consigo seu outrora contexto vivencial, pois como já explanado anteriormente neste artigo, tal aspecto o constitui enquanto ser social. Dessa forma, a escola também lida cotidianamente com essas diversidades e diferenças, lembrando que é de suma importância a acolhida por parte da instituição escolar e da sociedade, e que é preciso haver o respeito para com esses alunos, visto que, conforme Goellner (2010, p. 77):

\footnotetext{
Quando se fala em inclusão na educação dos corpos, dos gêneros e das sexualidades, afirma-se que os sujeitos são plurais e que essa pluralidade deve ser valorizada e aceita nas suas singularidades. Para tanto é necessário, de antemão, rejeitar os rótulos que aprisionam, engessam e fixam os sujeitos, enredando-os em representações que os nomeiam como feio ou bonito, apto ou inapto, saudável ou doente, normal ou desviante, masculino ou feminino, heterossexual ou homossexual. Precisamo-nos dar conta de que práticas como essas reforçam discriminações e exclusões, ao invés de ampliar possibilidades de intervenção junto aos sujeitos, possibilitando que, por meio das práticas corporais e esportivas, possam exercer sua cidadania e liberdade constituindo-se como sujeitos sociais (GOELLENER, p. 77. 2010).
}

Com todas essas diversidades presentes na sociedade, o ato de ensinar e educar torna-se um imenso desafio para os profissionais da educação, que lidam diariamente com os diversos tipos de indivíduos que constitui o meio escolar. Diante desse pressuposto, surgiu o interesse de pesquisar sobre a presença das diversas formas de diversidade na escola, com o intuito de identificar quais são as representações sociais dos profissionais da educação que se articulam dentre os alunos na instituição escolar, bem como analisar as práticas que esses profissionais têm utilizado para trabalhar com a diversidade existente entre os alunos.

\section{METODOLOGIA}

O presente estudo surgiu a partir de uma pesquisa de campo realizada em um município do interior do Estado de Mato Grosso do Sul. Com a intenção de atender as expectativas sobre o tema abordado, foram realizadas investigações bibliográficas e pesquisa de campo de natureza qualitativa. Para Lakatos e Marconi (2010, p. 166):

A pesquisa bibliográfica, ou de fontes secundárias, abrange toda bibliografia já tornada pública em relação ao tema de estudo, desde publicações avulsas, boletins, jornais, revistas, livros, pesquisas, monografias, teses, material cartográfico etc. [...] Dessa forma, a pesquisa bibliográfica não é mera repetição do que já foi dito ou escrito sobre certo assunto, mas propicia o exame de um tema sob novo enfoque ou abordagem, chegando a conclusões inovadoras.

Sob esse prisma, a abordagem teórica é entendida como uma investigação de extrema relevância para a construção de um artigo científico, por exemplo. Já a pesquisa de natureza qualitativa, pode proporcionar a concretização de uma hipótese de pesquisa, podendo enveredar 
para diversos fins, de forma a confirmar ou não a hipótese inicial indagada, pois se trata de uma pesquisa social. De acordo com Gil (1999, p. 26), “[...] a pesquisa social pode decorrer de razões de ordem intelectual, quando baseados no desejo de conhecer pela simples satisfação para agir”, evidenciando que a pesquisa qualitativa tem o intuito de apontar situações e fenômenos sociais. Para Bauer e Gaskell (2017, p. 11), “[...] a pesquisa qualitativa evita números, lida com interpretações das realidades sociais [...]. O protótipo mais conhecido é provavelmente, a entrevista em profundidade".

Como processo inicial da investigação, primeiramente foram realizados alguns contatos por telefone com a Secretaria Municipal de Educação do município pesquisado, a fim de obter a autorização para que a pesquisa fosse realizada em um das escolas públicas do ensino fundamental. Importante destacar que desde os primeiros contatos, todo o processo se deu muito receptivo, nos encaminhando para uma escola municipal situada na área periférica da cidade. Após a autorização foi feito contato com a gestora, sendo foi possível o agendamento do dia e horário levando em consideração a disponibilidade dos profissionais da educação que seriam entrevistados, para a realização da coleta de dados.

Posteriormente os integrantes do GEPDGE se deslocaram até o local indicado, para gravar entrevistas com a gestora da escola, uma funcionária que desenvolve atividades administrativas e duas professoras que vivenciam situações de diversidade entre os alunos. Sedo estas identificadas na discussão de dados da seguinte maneira:

Quadro 1 - Perfil dos participantes da pesquisa.

\begin{tabular}{|l|c|l|l|}
\hline IDENTIFICAÇÃO & IDADE & \multicolumn{1}{|c|}{ FORMAÇÃO } & ÁREA DE ATUAÇÃO \\
\hline Gestora & 56 & $\begin{array}{l}\text { Graduada em Economia } \\
\text { Doméstica e Licenciatura Plena. }\end{array}$ & Diretora de uma escola municipal. \\
\hline $\begin{array}{l}\text { Funcionária } \\
\text { Administrativa }\end{array}$ & 22 & Graduada em Administração. & Secretária Escolar. \\
\hline Professora 1 & 36 & Graduada em Pedagogia. & $\begin{array}{l}\text { Professora do primeiro ano do } \\
\text { ensino fundamental. }\end{array}$ \\
\hline Professora 2 & 28 & Graduada em Pedagogia & $\begin{array}{l}\text { Professora do segundo ano do } \\
\text { ensino fundamental }\end{array}$ \\
\hline
\end{tabular}

Fonte: Gonçalves e Ferreira (2019).

Diante das entrevistas realizadas nesta única escola, foi possível perceber que as mesmas ofereciam dados importantes para a concretização dos resultados da pesquisa, caracterizando a 
investigação como um estudo de caso, que para Santos (2001, p. 30), “[...] estudar um caso é selecionar um objeto de pesquisa restrito, com o objetivo de aprofundar-lhe os aspectos característicos. O objeto do estudo de caso pode ser qualquer fato/ fenômeno/processo individual, ou um de seus aspectos". De acordo com Fonseca (2002. p.33), o estudo de caso pode ser caracterizado como:

[...] um estudo de uma entidade bem definida como um programa, uma instituição, um sistema educativo, uma pessoa, ou uma unidade social. Visa conhecer em profundidade como o seu "como" e os "porquês" evidenciando a sua unidade e identidade próprias. É uma investigação que se assume como particularística, isto é, que se debruça deliberadamente sobre uma situação específica que se supões ser única em muitos aspectos, procurando descobrir o que há nela de mais essencial e característico.

Em todas as entrevistas realizadas, o instrumento utilizado para a pesquisa de campo se caracteriza por entrevistas semiestruturadas, caracterizada por um diálogo aberto que acontece entre pesquisador e sujeito, podendo os resultados tornar-se mais enriquecedores, corroborando com os processos da construção das pesquisas científicas que tem como intuito fazer novos apontamentos para o meio social. Nesse sentido, Triviños (1987, p. 146) conceitua entrevista semiestruturada da seguinte maneira:

Podemos entender por entrevista semi-estruturada, em geral, aquela que parte de certos questionamentos básicos, apoiados em teorias e hipóteses, que interessam à pesquisa, e que, em seguida, oferecem amplo campo de interrogativas, fruto de novas hipóteses que vão surgindo à medida que se recebem as respostas do informante. Desta maneira, o informante, seguindo espontaneamente a linha de seu pensamento e de suas experiências dentro do foco principal colocado pelo investigador, começa a participar na elaboração do conteúdo da pesquisa.

Após a realização da pesquisa de campo, os dados das entrevistas gravadas em áudio foram transcritos e sistematizados e então foram realizadas as discussões por meio de análise de conteúdo que, de acordo com Duarte (2004, p. 216):

Analisar entrevistas também é tarefa complicada e exige muito cuidado com a interpretação, a construção de categorias e, principalmente, com uma tendência bastante comum entre pesquisadores de debruçar-se sobre o material empírico procurando "extrair" dali elementos que confirmem suas hipóteses de trabalho e/ou os pressupostos de suas teorias de referência. Precisamos estar muito atentos à interferência de nossa subjetividade, ter consciência dela e assumi-la como parte do processo de investigação. 
Desse modo, é interessante que o pesquisador se mantenha neutro ao fazer uma análise de dados, cumprindo assim seu papel como cientista social. Por fim, os relatórios de pesquisa foram estruturados em forma de artigo científico, para que esses resultados sejam divulgados a toda população e também com o intuito de corroborar com os estudos científicos na área da Educação.

\section{RESULTADOS E DISCUSSÕES}

Ao tomar conhecimento adquirido mediante a junção de estudos bibliográficos e pesquisa de campo, a partir da coleta de dados, foi possível vislumbrar como a instituição escolar tem se posicionado diante da comunidade, no que se refere ao seu papel social, dado que esta tem relevância crucial no desenvolvimento humano, como aponta Louro (1997, p. 62) "Sob novas formas, a escola continua imprimindo sua 'marca distintiva' sobre os sujeitos. Através de múltiplos e discretos mecanismos, escolarizam-se e distinguem-se os corpos e as mentes." Sendo assim, estas instituições se constitui de seres variáveis em suas diversidades e identidades, cada qual com seu contexto, visão de mundo e diferenças.

Desse modo, pensando no contexto da escola municipal do ensino fundamental pesquisada, podemos perceber que esta encontra-se localizada em uma região periférica da cidade, lida com diversos tipos de alunos com situações socioeconômicas divergentes, como salienta a Funcionária Adm.: “[...] aqui nós temos crianças de toda faixa etária, tanto econômica quanto social”, já que muitas dessas crianças são filhos de pais da classe trabalhadora.

Um dos apontamentos que a Gestora faz como um dos grandes problemas presentes na escola devido essa situação socioeconômica, é a assiduidade, ela diz que "A cultura daqui é a assiduidade, é difícil, é muito difícil de você conquistar a assiduidade das crianças, a mãe trabalha, ela sai de madrugada pra ir para indústria, as crianças ficam dormindo, se está meio fresquinho, a criança já não vem pra escola”. Para Fernandes e Martins (2015, p. 2015).

[...] os estudantes que faltam às aulas perdem a possibilidade de nelas interagirem, tanto com o professor como com os colegas, de retirarem dúvidas face aos conteúdos lecionados, de estabelecerem um elo de ligação entre os conhecimentos anteriormente adquiridos e os novos e, não menos importante, de tirarem apontamentos acerca dos conteúdos da aula.

A perceber a falta constante dos alunos, a Gestora criou, juntamente com os profissionais da educação que ali atuam e com o apoio das famílias, vários projetos que incentivam o aluno a querer estar na 
sala de aula. Segundo Gadotti (1994, p. 579), “[...] Um projeto educativo pode ser tomado como promessa frente a determinadas rupturas. As promessas tornam visíveis os campos de ação possível, comprometendo seus atores e autores". Dentre esses projetos, destaca-se a gincana "Menos que vale mais", a qual significa que quanto menos o aluno falta, mais a sala se eleva na pontuação, para ganhar um "prêmio". A Gestora explana sobre essa gincana e também sobre outros projetos desenvolvidos, da seguinte forma:

[...] a gincana tem a participação dos pais e ela é constante, eles [os alunos] perdem ponto, número de faltas na sala, aí tem a pontualidade também, que eles eram super... Não tinham pontualidade, [...] O registro é um caderno que tem a história da sala inteirinha, e para recuperar os pontos, nós temos uma campanha que é a campanha da garrafa PET. Eu não sei se vocês viram que a cidade está sendo enfeitada todinha com garrafa PET. No ano passado, nós arrecadamos vinte e três mil garrafas PET nessa escola [...]. Nós também temos uma campanha do óleo usado, as crianças guardam o óleo em casa, trazem pra escola. E tem também a campanha da pilha, a gente recolhe todas as pilhas usadas para não ir para o meio ambiente. Acho que esse ano nós recolhemos uns vinte quilos de pilha. (GESTORA).

Diante desse relato, percebe-se que as crianças são muito participativas dessas campanhas e projetos, e que além de sanar o problema da assiduidade, sendo essa uma consequência da condição socioeconômica da região, as crianças também precisam agir em conjunto, unindo-se para que a pontuação da sala aumente, tendo como consequência um prêmio, que segundo a Gestora, se dá da seguinte maneira:

[...] todo final de mês, eu passo um quadro pra eles, tipo terceiro ano concorre com terceiro ano e a sala que vencer ganha um... Picolé, um pirulito, um filme, alguma coisa [...] Os terceiros e os quarto anos, no final do semestre ganha um piquenique. Entre as quatro turmas, a que se destacar mais ganha um piquenique. O quinto, o sexto e sétimo que tem poucas turmas, a gente juntou, vão à Campo Grande no cinema no shopping. É com esse dinheiro do óleo, das garrafas, que eles me pagam e a gente também pede ajuda da comunidade. (GESTORA).

Cabe salientar que esses projetos que prometam recompensas para as crianças, não são bem vistos por alguns pesquisadores, como é o caso de Vinha (1999, p. 37), que assim ressalta: "Não usamos recompensas ou punições com as crianças de forma alguma. Quando o adulto usa uma recompensa, quando dá alguma coisa em troca, quando fala que quem for bonzinho vai ficar no recreio, ele está manipulando para que a criança aja como ele quer".

Ainda assim, podemos perceber que nesta escola isso não acontece, a Gestora cita outro exemplo importante de incentivo para os alunos: 
Nós temos também a Geloteca, que são cinco geladeiras com livros, que ficam livre no corredor, livre para os alunos pegar os livros e devolver. Na hora do recreio, eles vão lá e lê, e assim a gincana foi agregando... agregando atividades. [...] Umas das atividades que a gente fez também é o recreio monitorado: a cada dia dez alunos de uma turma cuidam dos outros, eles ficam olhando, levam cordas, jogos de mesa, bola e são os responsáveis pelo material para as crianças brincarem. Eles levam coisas para brincar e ao final eles recolhem. Aí eles têm um colete escrito "Monitor" atrás, é bem chique! O colete é laranja e é possível enxergar eles de longe. Os monitores do dia vêm ali, pega o colete, coloca e vão cuidar do recreio. (GESTORA).

Parece que por meio dos projetos desenvolvidos, a comunidade escolar envolvida tem conseguido atingir um resultado final positivo, que vai além de um simples piquenique, por exemplo, pois o caminho que as crianças tiveram que percorrer para chegar ao resultado, pode se caracterizar como uma grande trajetória de conhecimento, por proporcionar aos alunos momentos de lazer e confraternização, ajuda mútua, responsabilidade, autonomia, respeito consigo, com o próximo e com o meio.

O fato de ir até a capital do Estado de Mato Grosso do Sul, pode ser uma oportunidade para que adolescentes, que jamais saíram do município, possam fazê-lo, dando a entender que através desses projetos, as crianças e adolescentes possam ampliar seus valores e suas visões de mundo, buscando nos estudos um meio para mudar suas situações socioeconômicas. Nesse sentido, André (2016, p. 20) sinaliza que formar indivíduos com autônomia é formar:

[...] pessoas que tenham ideias próprias, pensem por si mesmas, sejam capazes de escolher entre alternativas, decidam o caminho a ser seguido, implementem ações e tenham argumentos para defender suas escolhas e ações. Ao exercer sua autonomia, essas pessoas vão se sentir cada vez mais livres das amarras do poder político e econômico.

A respeito dessa vertente, a devida escola indica estar cumprindo seu papel. Ao abordar sobre diversidade de inclusão social, existe um fato muito interessante ocorrido na escola e que foi mencionado pela Gestora, ao se referir ao tema preconceito durante a entrevista. Nesse sentido, ela exemplifica que:

[...] eu tenho um menino que usa prótese da perna, ele nasceu com problema e usa uma prótese, nunca! Eu vi uma criança fazer uma chacota com menino nem nada, ele vem de bermuda com a prótese aparecendo. $\mathrm{Na}$ aula de educação física eles querem ajudar, ainda ele tá fazendo o slackline ${ }^{3}$, aí ele não conseguia subir, ficou um de cada lado ajudando ele, [subir] o professor até tirou uma foto, eu até saí na hora que eu vi e fiquei emocionada, as crianças não têm esse tipo de problema. (GESTORA).

\footnotetext{
${ }^{3}$ O Slackline em é um elástico esticado entre dois pontos fixos, permitindo que o praticante possa andar e fazer manobras por cima (Blog Léo Tubarão, Globo Esportes.com).
} 
Diante dessa fala podemos perceber que além de um trabalho intenso por parte dos profissionais da educação, os efeitos dos projetos são notáveis entre as crianças. Ao abordar sobre diversidade de gênero, sexual e familiar nas entrevistas, podemos detectar também algumas representações sociais por parte das profissionais diante das temáticas. Dessa maneira, “[...] tornase um desafio então, para as instituições escolares, acompanhar as transformações sociais que ocorrem ao longo do tempo" (PALMA; STREY, 2015, p. 6-7).

Deste modo, ao tratar sobre a diversidade familiar presentes na escola, a Gestora faz a seguinte exposição: "É uma situação social complicada, que eu acho que eles veem a escola como porto seguro, eu tenho bastante criança assim. São bem poucas as que têm pai e mãe bonitinho. É padrasto, madrasta, tem uma outra constituição, vó, vô...”. De forma semelhante, a Professora 1 destaca:

\footnotetext{
O que eu penso... que é com o tempo foi se desgastando muito a família né, ela foi se desestruturando. Aqui mesmo na escola, como eu acabei de dizer, são bem desestruturadas as famílias e eu acho assim que está perdendo o foco principal da família, de ter pai mãe e filhas, né. Acho que é algo assim (PROFESSORA 1).
}

No mesmo enfoque, ao falar sobre as famílias dos alunos que frequentam a escola, a Professora 2 reflete: "É difícil. A gente é meio tradicionalista, né. É geração nossa, mas a gente tem que se adaptar, tem que preparar as crianças para isso também, né”. Para Belfort; Barros; Gouveia e Santos (2015, p. 44), “As famílias que não conseguem realizar as próprias funções são consideradas desestruturadas, desintegradas ou desorganizadas". Mesmo deixando vir à tona suas representações sociais de gênero, em relação aos novos modelos familiares, a Gestora e a Professora 2 apontam que a condição familiar da criança não interfere no dia-dia escolar dela, pois os profissionais estão preparados para lidar com esses temas transversais. Ela diz que "Isso não interfere em nada!", corroborando com a Professora 2 que destaca: "Não acaba interferindo, né. Quando a gente é preparado já pra isso, para preparar as crianças, então não interfere, não muda nada não".

Nesse sentido, a Funcionária Adm. que também acompanha os recreios, completa dizendo que as crianças também não sofrem preconceitos por serem integrantes de famílias não convencionais. Ela menciona que “[...] até hoje, ninguém chegou e falou 'Olha tia, ele tá, tá tirando 
sarro por a minha família ser diferente"'. Diante desses relatos, podemos perceber que isso ocorre devido ao contexto social que as crianças estão inseridas, tornando-se normais para elas esses tipos de situações. A atuação dos educadores que, deixam suas subjetividades a parte, também corroboram com este quadro. Deste modo, Estevam, Moraes, Ignatti e Souza, (2011, p. 10) explanam que:

\footnotetext{
Sabemos o quanto as práticas diárias vividas pelo professor em sala de aula durante o seu trabalho pedagógico, constituem-se em momentos adversos que oscilam desde angústias pela busca de melhores caminhos para atingir os objetivos inerentes a sua profissão, ou seja, de formar o discente um indivíduo crítico e capaz de exercer a plena cidadania, até nas escolhas, que por vezes são consideradas conflituosas para o docente, dos conteúdos que deverão ser realmente ensinados e poderão fazer significado para o aprendiz.
}

Em um dado momento da entrevista, a Gestora cita que essa preparação acontece devido a todos os profissionais da educação receberem formação para aprenderem a lidar com as diversidades existentes na escola: "A formação continuada começou aqui em 2002 com o PCN, depois aí foi e foi... Sempre nós temos $\mathrm{X}$ horas por ano de formação, aí vem palestrante de fora, vem faz oficinas. Tem, por exemplo uma formação sobre "Aprendendo as Diferenças", acho que era esse o tema" (GESTORA). Para Gatti (2016, p. 170):

\footnotetext{
Ter presente a diversidade de necessidades e de condições pode enriquecer a reflexão e orientar com mais segurança, a formação de base e a continuada de docentes, a qual merece se diversificar em formas curriculares variadas, próprias a uma sócio-culturalidade rica e múltipla como é a do Brasil.
}

A Gestora menciona também sobre as questões da diversidade de gênero na escola, e que embora já tenham acontecido pequenos atritos entre os alunos, o problema logo foi sanado pelos profissionais da educação. Assim, a Gestora cita o exemplo de dois alunos homossexuais que eram “[...] bem tranquilos os alunos. Eram amigos de todo mundo!” Ela argumenta que um deles, dos anos finais do ensino fundamental, se vestia de mulher e "queria entrar na fila das meninas". Nesse caso, o único problema que enfrentou foi com os pais, em relação ao uso dos banheiros, pois não aceitavam o aluno no banheiro feminino e nem no masculino. Assim, logo a Gestora encontrou uma solução: "Eu disponibilizava, para ele para evitar qualquer tipo de problema, o banheiro do administrativo". 
Em relação à sexualidade, ela conta que teve um terceiro aluno homossexual, que causou desconforto em outros alunos, por motivo de assédio e que logo ela o chamou para conversar, com os seguintes argumentos:

- Gestora: Aqui dentro, assim..., menino e menina pode namorar aqui dentro?

- Aluno: Não!

- Gestora: Pode ficar dando beijo na boca?

- Aluno: Não!

- Gestora: Então você também tem que se comportar! A norma vale para todo mundo, não tem norma diferente para os alunos.

A Gestora explicou que a partir desse dia não ocorreu mais o assédio. O que a Gestora demonstra é que os meninos homossexuais não sofriam bullyng ou preconceito por parte dos outros alunos e tinham uma boa convivência com os colegas na escola, ainda que um deles tenha assediado outros alunos heterossexuais, deixando-os desconfortáveis. Com a ação prática imediata da Gestora, o problema logo foi sanado. Vale destacar que na maioria dos casos é o homossexual que sofre assedio, visto que ao explanar sobre as formas de bullying, Silva $(2015$, p. 12) postula que "[...] esse tipo de comportamento desprezível costuma ocorrer entre meninos com meninas e entre meninos com meninos, não raro o estudante indefeso é assediado e violentado por vários colegas ao mesmo tempo". No caso da escola pesquisada, parece que não eram os alunos homossexuais que sofriam preconceitos e sim os heterossexuais é que eram assediados pelos primeiros.

Ainda sobre a diversidade sexual, as entrevistadas expõem que acontecem algumas situações, entre os adolescentes que querem namorar dentro espaço escolar: "Um caso é um rapazinho que queria namorar a menina e daí ficava se beijando e aqui não pode [...] Aí eu chamo e passo para a direção" (FUNCIONÁRIA ADM.). Segundo ela, tal fato ocorre devido a faixa etária de idade dos alunos do $6^{\circ}$ ao $7^{\circ}$ ano, ou seja, a fase da adolescência, que é entendido como:

[...] um período muito especial no desenvolvimento humano, considerada a transição entre a infância e a idade adulta, caracterizada por intenso crescimento e desenvolvimento que se manifesta por marcantes transformações anatômicas, fisiológicas, psicológicas e sociais. Em um contexto mais psicológico, é a etapa na qual o indivíduo busca a identidade adulta, apoiando-se nas primeiras relações afetivas, já interiorizadas, que teve com seus familiares e verificando a realidade que a sua sociedade lhe oferece. (BRÊTAS; OHARA; JARDIM; JUNIOR; OLIVEIRA, 2001, p. 2). 
Já ao abordar sobre a curiosidade de crianças pequenas em relação à sexualidade, a Funcionária Adm. diz nunca ter presenciado nada nesse sentido, até porque existem “[...] pessoas que ficam no banheiro, na porta do banheiro ali, justamente para evitar quê... No recreio, fica gente cuidando". Ao refletir sobre a vigilância da sexualidade infantil, Louro (2000, p. 15) enfatiza que: “[...] redobra-se ou renova-se a vigilância sobre a sexualidade, mas essa vigilância não sufoca a curiosidade e o interesse, conseguindo, apenas, limitar sua manifestação desembaraçada e sua expressão franca". Assim, é possível que a crianças podem não manifestar suas curiosidades, dentro do banheiro, mas ainda assim tais curiosidades podem vir a acontecer em algum outro momento ou local.

Em se tratando da maneira como deve ser trabalhado, para respeitar as diferentes formas de diversidade na escola, todas as participantes da pesquisa concordam que o tema deve ser abordado, como sugere a Professora 1 “[...] é trabalhar com certeza né, explicando as diferenças, as pessoas optam por aquilo que elas querem ser né". Também deve ser discutido de acordo com a necessidade, segundo a opinião da Gestora: "Esses são assuntos que você tem que trabalhar, dia a dia, são temas transversais que você não pode esquecer nunca". Louro (2000, p. 71) assim aponta: “[...] poderíamos pensar na forma como o sexo torna-se sujeito a questões mais amplas, que organizam os esforços pedagógicos e que cobrem as relações entre crianças e adultos, entre a casa e a escola e entre a identidade e sua representação". Sendo assim, percebendo que a sexualidade faz parte do desenvolvimento dos alunos, os relatos das entrevistadas, em concordância com o apontamento de Louro (2000), indicam que se deve sim trabalhar temáticas relativas à sexualidade na instituição escolar.

Ao trazer à tona a diversidade de gênero entre meninos e meninas, a Funcionária Adm. aponta que deve haver respeito mútuo entre eles, mas que ainda assim os meninos causam um pouco mais de transtorno principalmente na hora do recreio. Segundo ela isso ocorre pois:

Um menino quer mostrar para o outro que é melhor [...] eles estão na faixa etária bem complicada né, se descobrindo. Eles não sabem o que eles querem ainda, o que querem ser, o que vão ser futuramente. Aí eles veem colega como uma maneira de se achar um pouquinho melhor (FUNCIONÁRIA ADM.)

Para Boris (2008, p. 4), “[...] desde a infância até à idade adulta, e muitas vezes durante toda a vida, a masculinidade é muito mais uma reação inconsciente do que uma adesão consciente". 
Dessa forma, os meninos aprendem desde a primeira infância que devem se auto afirmar todo o tempo diante do meio, podendo conquistar assim seu lugar de macho na sociedade.

Ao abordar a diversidade étnica, houve um caso importante destacado pela gestora. Ela recorda, que quando a escola recebeu um aluno que veio junto com sua família para o Brasil, sendo estes refugiados do Líbano, o menino:

[...] chegou aqui, ele estava fazendo o Kumon para falar português. A sociedade acolheu ele e logo a professora da escola de Kumon já pegou o menino para estudar português. Ele veio para escola, ele não falava. Dava aula com celular, mostrava as coisas no celular para ele. No primeiro alguns alunos correram atrás desse guri por causa do sotaque e queriam que ele falasse. Então começaram a ensinar palavrão para ele [...] Nós temos um sistema de som integral aqui, eu peguei o microfone e falei para eles, de onde o menino era, que o menino vinha de uma guerra, "pararararara". Agora ele está super bem, super bem adaptado na escola, é um dos melhores alunos hoje (GESTORA).

Diante desse fato, o agir imediato da Gestora segere que, quando os alunos passaram a conhecer o contexto histórico do menino libanês, passaram também a acolhê-lo e assim trataramno com o devido respeito que este merecia. Carlet e Milesi (2006) se enveredam pela lei que garante os direitos dos refugiados no Brasil, ao enfatizar que:

\footnotetext{
A Lei 9.474/97, além de ser um avanço na internalização do Direito Internacional dos Refugiados, constituiu-se também numa política pública de amplo significado nesta causa. Com o amadurecimento da temática e o debate sobre a importância do acesso dos refugiados à educação, ao trabalho, à saúde, à moradia, ao lazer, o Brasil vem reconhecendo, em termos legais e teóricos, a necessidade de implementação de políticas públicas específicas e a possibilidade de acesso dos refugiados às políticas existentes, ao amparo, como já dissemos, da disposição constitucional de tratamento paritário entre nacionais e estrangeiros residentes no país. (CARLET; MILESI, 2006, p. 134).
}

Desse modo, quando um indivíduo refugiado chega ao Brasil, ele passa a ser acolhido pela comunidade e órgãos governamentais onde ele se situa. Vale ressaltar sobre a dificuldade que essas pessoas encontram ao tentarem se instalar em outro país, lembrando que geralmente esses sujeitos trazem consigo uma história de sofrimento e perda. Ainda que a criança do Líbano tenha causado um breve alvoroço entre os alunos da escola pesquisada, a partir da ação da gestora, a escola pôde, em mais um ato, cumprir seu papel, o de fazer com que todos se respeitem em suas diferenças, mediante um processo de acolhida, interação e troca de culturas e conhecimentos, que todas essas diversidades proporcionam, corroborando com o processo de formação de cidadãos conscientes. 


\section{CONSIDERAÇÕES FINAIS}

Diante de todos esses temas abordados sobre os tipos de diversidades existentes na escola, foi possível perceber, dentro dessa linha de pesquisa, que a escola investigada é de fato um berçário social, ou seja, a criança é recebida junto com sua família na instituição, e passa a ser construído enquanto ser social de maneira muito positiva. A escola, que atende uma clientela de área periférica, busca proporcionar momentos de interação social e instigar, mediante o desenvolvimento de projetos e práticas realizadas pelos profissionais da educação, o respeito mútuo entre os alunos.

Ao mesmo tempo, são proporcionadas um crescimento intelectual e humanístico, pois as práticas são adotadas pelos profissionais da educação, que participam de um processo de formação continuada anualmente. Assim, eles têm condições de atuar de uma forma mais profissional, mesmo que tenham consigo suas próprias representações sociais, diante de alguns tipos de diversidade.

No tocante, podemos apontar que os alunos têm também uma grande capacidade de superação e aceitam de maneira tranquila o processo de desnaturalização sobre várias temáticas, mesmo que muitas vezes esse processo se forma de maneira inconsciente pelos alunos, já que convivem em meios sociais que lhes proporcionam uma melhor acessão sobre os novos tipos de diversidade e as diferenças que estão impostas a esta.

Por fim, vale ressaltar que todos os sujeitos dessa pesquisa falaram muito sobre afeto e conhecimento da realidade do aluno, para então compreendê-lo e então respeitá-lo. Desse modo, podem elaborar e desenvolver práticas pedagógicas mais eficientes.

Diante desses pressupostos, é possível dizer que ao ser realizada a análise de dados de maneira minuciosa, foi possível notar o forte envolvimento de toda a comunidade escolar presentes na instituição, visto que essas práticas parecem que estão dando certo. Como o fato de perceber que família e escola trabalham com um único intuito: o de corroborar com o desenvolvimento integral e crítico das crianças e adolescentes ali presentes. Sendo assim, esse fato indica que, devido aos comportamentos apresentados pelos alunos, diante da união famíliar e práticas escolares, a instituição escolar pesquisada tem cumprido um importante papel social diante da comunidade.

\section{REFERÊNCIAS}

ANDRÉ, M. Práticas inovadoras na formação de professores. Campinas: Papirus, 2016.

ARIÈS, P. História social da criança e da família. Rio de Janeiro. $2^{\mathrm{a}}$ ed. Zahar Editores.1981.

BARDIN, L. Análise de conteúdo. Lisboa/Portugal: Edições 70, 2004.

Cadernos Cajuína, V. 5, N. 1, 2020, p. 127-147. 
BELFORT, P. B.; BARROS, S. M. M. de; GOUVEIA, M. L.A.; SANTOS, M. F. S. Representações sociais de família no contexto do acolhimento institucional. Revista Psicologia: Teoria e Prática. São Paulo, v. 17, no 3, p. 42-51, set/dez., 2015.

BRASIL. Constituição. Constituição da República Federativa do Brasil. Brasília, DF: Senado, 1988.

BRASIL. Declaração de Salamanca e linha de ação sobre necessidades educativas especiais. Brasília: UNESCO, 1994. Disponível em:

<http://portal.mec.gov.br/seesp/arquivos/pdf/salamanca.pdf> Acessado em: 10 abr. 2019.

BRASIL. Ministério de Educação e Cultura. LDB - Lei $\mathbf{n}^{\mathbf{0}}$ 9394/96, de 20 de dezembro de 1996. Estabelece as diretrizes e bases da Educação Nacional. Brasília: MEC, 1996.

BRASIL. Ministério da Educação e do Desporto. Secretaria da Educação Fundamental.

Referencial Curricular Nacional para Educação Infantil. v.1-3. Brasília, DF:

MEC/SEF/Coedi, 1998.

BAUER, M. W. GASKELL, G. Pesquisa qualitativa com texto, imagem e som: um manual prático, Tradução de Pedrinho Guarechi, Petrópolis, Rio de Janeiro: Vozes. 2017.

BORIS, G. D. J. B. Versões de sentido: um instrumento fenomenológico-existencial para a supervisão de psicoterapeutas iniciantes. Psicologia Clínica, Rio de Janeiro, v. 20, n. 1, p. 165 $180,2008$.

BRÊTAS, J. R. da; OHARA, C.V. S. ; JARDIM, D.P.; JUNIOR, W. A; OLIVEIRA, J. R. de. Aspectos da sexualidade na adolescência, Ciência e Saúde Coletiva, São Paulo, v. 16, n. 7 , p. 3221- 3228, jul. 2011.

CARLET, F.; MILESI, Rosita. Refugiados e políticas públicas. In: RODRIGUES, V. (Org.). Direitos humanos e refugiados. Vila Velha/Espírito Santo: Nuares - Centro Universitário Vila Velha; ACNUR; IMDH, 2006. p. 134.

DAYRELL, J. A escola como espaço sociocultural. In: DAYRELL, J. (Org.). Múltiplos olhares sobre educação e cultura. Belo Horizonte: UFMG, 1996.

DUARTE, R. Entrevistas em pesquisas qualitativas. Educar UFPR. Curitiba. 2004.

ESTEVAM,S.J; IGNATTI, C.; MORAES, P.R.de; SOUZA, J.C.de. A importância da construção do projeto político pedagógico na formação do professor. Educação em Foco, set. 2013.

Disponível em:

$<$ http://unifia.edu.br/revista_eletronica/revistas/educacao_foco/artigos/ano2013/setembro/fo rmacao_continuada.pdf $>$. Acesso em: 17 ago. 2019.

FERNANDES, G.; MARTINS, J. A. Influência da assiduidade no processo de ensinoaprendizagem no ensino Politécnico. Situação e estratégias no Instituto Politécnico da Guarda 
IPG-Portugal. Congresos CLABES. Revistas.UTP, Chile, 2015. Disponível em:

<http://www.revistas.utp.ac.pa/index.php/clabes/article/view/1129> Acesso em: 10 jul. 2019.

FERNANDES, J. R. O. Ensino de história e diversidade cultural: desafios e possibilidades.

Cadernos Cedes, Campinas, v. 25, n. 67, p. 378-388, set./dez. 2005.

FONSECA, J.J.S. da. Metodologia da pesquisa cientifica. Ceará: UECE, 2002

FORNEIRO, L. I. A Organização dos Espaços na Educação Infantil. In: ZABALZA, M. A. Qualidade em educação infantil. Porto Alegre: Artmed, 1998.

GATTI, B. A. Formação de professores: condições e problemas atuais. Revista Internacional de Formação de Professores (RIPF), Itapetinga, v. 1, n.2, p. 161-171, 2016. Disponível em: < http://itp.ifsp.edu.br/ojs/index.php/RIFP/article/view/347/360> Acesso em: 14 jul. 2019.

GIL, A. C. Métodos e técnicas de pesquisa social. São Paulo: Atlas, 1999.

GOELLNER, S. V. A educação dos corpos, dos gêneros e das sexualidades e o reconhecimento da diversidade. Cadernos de Formação RBCE, v. 1, n. 2, p. 71-83, mar., 2010.

JODELET, D. La representación social: Fenómenos, concepto y teoría. In: MOSCOVICI, S. Psicologia Social. Barcelona: Paídos, 1985, p. 469-494.

LAKATOS. E. M.; MARCONI, M. A. Fundamentos de Metodologia Científica. São Paulo: Atlas, 2010.

LOURO, G. L. Gênero, sexualidade e educação. Uma perspectiva pós-estruturalista.

Petrópolis: Vozes, 1997.

LOURO, G. L. O corpo educado: pedagogias da sexualidade. 2. ed. Tradução dos artigos: Tomaz Tadeu da Silva. Belo Horizonte: Autêntica, 2000.

LOURO, G. L. Gênero e sexualidade: pedagogias contemporâneas. Pro-Posições, Campinas, v. 19, n. 2, p. 17-23, ago., 2008.

MELLO, P. C. Estrangeiros buscando refugio no Brasil mais que dobram em um ano. Folha de São Paulo. São Paulo, 19 jun. 2018. Disponível em:

<https://www1.folha.uol.com.br/mundo/2018/06/estrangeiros-buscando-refugio-no-brasilmais-que-dobraram-em-um-ano.shtml. Acesso em: 14 jul. 2019.

PALMA, Y. A.; STREY, M. N. A relação família e escola: a diversidade familiar compondo o contexto escolar. Revista de Psicologia. Chile, v. 24, n. 1, p. 1-17, out., 2015. Disponível em: <file://C:/Users/User/Downloads/36918-1-127057-3-10-20150801.pdf>. Acesso em: 17 ago. 2019. 
SANTOS, A. R. dos. Metodologia científica: a construção do conhecimento. Rio de Janeiro: DP\&A, 2001.

SILVA, A. B. B. Bullying Mentes Perigosas nas escolas: como identificar e combater a violência o preconceito na escola. São Paulo: Principium, 2015.

SILVA, T. Ta. Identidade e diferença: a perspectiva dos estudos culturais. Petrópolis, RJ: Vozes, 2000.

SCHMIDT, S. P. Gênero e história no romance português: novos sujeitos na cena contemporânea. Porto Alegre: Edipucrs, 2000.

SCOTT, J. W. Gênero: uma categoria útil de análise histórica. Educação \& Realidade. Porto Alegre, v. 20, nº 2, jul./dez. 1995.

SPINK, M. J.; MEDRADO, B. Produção de sentido no cotidiano: Uma abordagem teóricometodológica para análise das práticas discursivas. In: M. J. Spink (Org.) Práticas discursivas e produção de sentidos no cotidiano: Aproximações teóricas e metodológicas São Paulo: Cortez. 2013, p. 41-61.

TRIVIÑOS. A. N.S. Introdução à pesquisa em Ciências Sociais: A pesquisa qualitativa em educação. São Paulo: Atlas, 1987.

VINHA, T. P. O educador e a moralidade infantil numa perspectiva construtivista. São Paulo: Cogeime, 1999. 